\title{
TTP-like syndrome: novel concept and molecular pathogenesis of endotheliopathy-associated vascular microthrombotic disease
}

\author{
Jae C. Chang(D)
}

\begin{abstract}
TTP is characterized by microangiopathic hemolytic anemia and thrombocytopenia associated with brain and kidney dysfunction. It occurs due to ADAMTS13 deficiency. TTP-like syndrome occurs in critically ill patients with the similar hematologic changes and additional organ dysfunction syndromes. Vascular microthrombotic disease (VMTD) includes both TTP and TTP-like syndrome because their underlying pathology is the same disseminated intravascular microthrombosis (DIT). Microthrombi are composed of platelet-unusually large von Willebrand factor multimers (ULVWF) complexes. TTP occurs as a result of accumulation of circulating ULWWF secondary to ADAMTS13 deficiency. This protease deficiency triggers microthrombogenesis, leading to "microthrombi" formation in microcirculation. Unlike TTP, TTP-like syndrome occurs in critical illnesses due to complement activation. Terminal C5b-9 complex causes channel formation to endothelial membrane, leading to endotheliopathy, which activates two different molecular pathways (i.e., inflammatory and microthrombotic). Activation of inflammatory pathway triggers inflammation. Activation of microthrombotic pathway promotes platelet activation and excessive endothelial exocytosis of ULWWF from endothelial cells (ECS). Overexpressed and uncleaved ULVWF become anchored to ECs as long elongated strings to recruit activated platelets, and assemble "microthrombi". In TTP, circulating microthrombi typically be lodged in microvasculature of the brain and kidney, but in TTP-like syndrome, microthrombi anchored to ECs of organs such as the lungs and liver as well as the brain and kidneys, leading to multiorgan dysfunction syndrome. TTP occurs as hereditary or autoimmune disease and is the phenotype of ADAMTS13 deficiency-associated VMTD. But TTP-like syndrome is hemostatic disorder occurring in critical illnesses and is the phenotype of endotheliopathy-associated VMTD. Thus, this author's contention is TTP and TTP-like syndrome are two distinctly different disorders with dissimilar underlying pathology and pathogenesis.
\end{abstract}

Keywords: ADAMTS13, Complement, Disseminated intravascular coagulation (DIC), Disseminated intravascular microthrombosis (DIT), Endotheliopathy, Microthrombogenesis, Thrombotic thrombocytopenic purpura (TTP), TTPlike syndrome, Unusually large von Willbrand factor multimers (ULWWF), Vascular microthrombotic disease (VMTD)

(c) The Author(s). 2018 Open Access This article is distributed under the terms of the Creative Commons Attribution 4.0 International License (http://creativecommons.org/licenses/by/4.0/), which permits unrestricted use, distribution, and reproduction in any medium, provided you give appropriate credit to the original author(s) and the source, provide a link to the Creative Commons license, and indicate if changes were made. The Creative Commons Public Domain Dedication waiver (http://creativecommons.org/publicdomain/zero/1.0/) applies to the data made available in this article, unless otherwise stated. 


\section{Background}

The new term vascular microthrombotic disease (VMTD) has been used [1-3], but has not been designated as a disease entity yet. Both microvascular thrombosis and vascular microthrombosis have been used interchangeably to describe the similar pathological conditions. Disseminated VMTD represents both TTP and TTP-like syndrome, but the identity of TTP-like syndrome has not been clearly defined to date.

TTP is characterized by microvascular thrombosis associated with markedly decreased ADAMTS13 activity due to mutation of ADAMTS13 gene (hereditary) or due to antibody against ADAMTS13 (acquired). Hematologic phenotype is consumptive thrombocytopenia and microangiopathic hemolytic anemia (MAHA) as a result of disseminated intravascular microthrombosis (DIT) [2, 4]. Organ involvement occurs typically in the brain and kidneys. DIT is the pathological condition caused by vascular "microthrombi", which are exclusively composed of the complexes of platelet and unusually large von Willbrand factor multimers (ULVWF) in various organs [4-6]. In 1924, Eli Moschcowitz first recognized a thrombotic blood disorder characterized by disseminated hyaline microthrombi in terminal arterioles and capillaries of organs in a young woman who died at the Beth Israel Hospital in New York City [7]. Later, Singer et al. named this disorder thrombotic thrombocytopenic purpura (TTP) [8].

Other focal, multifocal or localized microvascular thrombosis also exists without proper name designation. Appropriate medical term could be focal, multifocal or localized VMTD. These may include ischemic stroke syndrome (e.g., transient ischemic attack) $[9,10]$ and myocardial ischemia (e.g., angina) [10]. Also, focal endotheliopathy in HERNS disease and Susac syndrome as well as localized endotheliopathy in Kasabach-Merritt syndrome are suspected to be due to microthrombosis in smaller or larger vasculatures. These syndromes cannot be designated as TTP because their involvement in the organs is not generalized and is usually not associated with thrombocytopenia and MAHA.

More recently, TTP-like syndrome has been frequently reported. It is also characterized by vascular microthrombosis with thrombocytopenia and MAHA, but commonly atypical organ dysfunction syndromes such as acute respiratory distress syndrome (ARDS), rhabdomyolysis, acute fulminating hepatic failure, and pancreatitis have occurred. These syndromes are also characterized by DIT [1-3]. Therefore, to properly classify TTP-like syndrome in the category of VMTD, there is a need for differentiating between TTP and acquired TTP-like syndrome and identifying the pathogenesis of TTP-like syndrome since it is not associated with ADAMTS13 antibody.

\section{TTP-like syndrome}

TTP typically involves the brain and kidneys, but TTP-like syndrome prominently develops in one or more of vital organs [11-14], including the liver $[15,16]$, heart [17, 18], lungs [11-13, 19, 20], pancreas [21] and others with or without involvement of the brain and kidneys. Oftentimes fewer schistocytes are present on the blood film and intravascular hemolysis could have easily missed [11, 13]. Since MAHA is not overt because of fewer schistocytes, the diagnosis of TTP-like syndrome could have been masked even though thrombocytopenia was present [2]. Because of less prominent nature of schistocytes, it has been termed atypical MAHA (aMAHA) [1, 2]. The most notable observation of TTP-like syndrome is its frequent occurrence in critical illnesses such as infection, sepsis, trauma, cancer, autoimmune disease, malignant hypertension, drug and toxin, envenomation, and complications of pregnancy, surgery and transplant (Table 1).

In the early 1980s, Moake et al. made a very important discovery that ULVWF contributed to the pathogenesis of TTP [22]. Furlan et al. [23] and Tsai [24] independently published the presence of VWF-cleaving protease, and subsequently the deficient role of this protease ADAMTS13 due to anti-ADAMTS13 antibody was established.

Prior to the role of autoantibody was recognized, clinicians accepted the use of the term TTP whenever a patient presented with the dyad of thrombocytopenia and MAHA, even though obvious organ dysfunction was not present yet [12]. This dyadic feature was considered to be sufficient criteria to make the diagnosis of TTP for the purpose of initiating urgent therapeutic plasma exchange (TPE) to save lives [11-13]. The generic term TTP, encompassing both TTP and TTP-like syndrome, has served well for the patient by allowing TPE when presented with thrombocytopenia and MAHA/ aMAHA even though organ dysfunction is not developed yet. TPE has been very effective and life-saving measure in both disorders when it was employed in the earliest possible time [2, 11-13, 20].

Because of common occurrence of TTP with acute renal failure/hemolytic-uremic syndrome (HUS) in clinical medicine, the combined term TTP-HUS also has been in use to include both TTP and TTP-like syndrome to date [25] even though the pathogenesis and clinical features of HUS are clearly different from TTP [3]. In retrospect, this combined term might have contributed to the masking of TTP-like syndrome and VMTD when organ dysfunction developed in other than the brain and kidneys. It also has delayed identifying the multifaceted pathogenesis of TTP-like syndromes. In addition, this terminology could have kept disseminated intravascular coagulation ("DIC") as a different disease from TTP-like 
Table 1 Genesis and characteristics of VMTD in TTP and TTP-like syndrome

\begin{tabular}{|c|c|c|}
\hline & $\begin{array}{l}\text { Hereditary TTP (GA-VMTD) } \\
\text { Acquired TTP (AA-VMTD) }\end{array}$ & TTP-like syndrome (EA-VMTD) \\
\hline Primary causes/events & $\begin{array}{l}\text { Hereditary ADAMTS13 gene mutation } \\
\text { Acquired ADAMTS13 antibody formation } \\
\downarrow\end{array}$ & $\begin{array}{l}\text { Pathogen (e.g., viruses; bacteria; fungi; rickettsia; parasites) } \\
\text { Polytrauma (e.g., chest/lung; bone; skull/brain injury) } \\
\text { Pregnancy (e.g., preeclampsia; abruptio placenta; amniotic fluid } \\
\text { embolism) } \\
\text { Cancer (e.g., disseminated stomach/breast/lung cancer) } \\
\text { Transplant (e.g., liver; kidney; bone marrow) } \\
\text { Drug and toxin (e.g., cyclosporine; mitomycin C; Shiga toxin) } \\
\downarrow\end{array}$ \\
\hline Secondary event & $\begin{array}{l}\text { Excessive circulating mULWWF } \\
\downarrow\end{array}$ & $\begin{array}{l}\text { Complement activation (C5b-9) and endothelial injury } \rightarrow \\
\text { endotheliopathy } \\
\downarrow\end{array}$ \\
\hline Tertiary event & $\begin{array}{l}\text { Microthrombogenesis } \rightarrow \text { platelet-ULWWF complexes } \\
\downarrow \\
\text { Microthrombi lodged in arteriolar and capillary } \\
\text { lumens } \\
\downarrow\end{array}$ & $\begin{array}{l}\text { Cytokine release } \rightarrow \text { inflammation } \rightarrow \text { SIRS } \\
\text { Platelet activation and endothelial exocytosis of eULWWF } \\
\downarrow \\
\text { Microthrombogenesis } \rightarrow \text { platelet-ULWWF complex strings } \\
\downarrow\end{array}$ \\
\hline Final event & $\begin{array}{l}\text { Microvascular microthrombosis } \\
\downarrow \\
\text { DITNMTD } \\
\downarrow \\
\text { TTP }\end{array}$ & $\begin{array}{l}\text { Vascular microthrombosis } \\
\downarrow \\
\text { DITNMTD } \\
\downarrow \\
\text { TTP-like syndrome }\end{array}$ \\
\hline \multicolumn{3}{|l|}{ Hematologic features } \\
\hline Platelet & Consumptive thrombocytopenia & Consumptive thrombocytopenia \\
\hline Red blood cell & MAHA & MAHA/aMAHA \\
\hline \multicolumn{3}{|l|}{ Clinical syndromes } \\
\hline Inflammation & Uncommon & Very common \\
\hline Cytokine storm & Absent & Often present in sepsis and MODS \\
\hline SIRS & Absent & Often present in sepsis and MODS \\
\hline Encephalopathy & Very common & Common, especially in HUS \\
\hline ARDS & Probably absent & Common \\
\hline AFHF & Probably absent & Common, sometimes with hepatic coagulopathy \\
\hline ARF/HUS & Very common & Common \\
\hline "DIC" (see text) & Doesn't occur & Identical to TTP-like syndrome \\
\hline \multicolumn{3}{|l|}{ Laboratory features } \\
\hline ADAMTS13 activity & Markedly decreased (<5\% of normal) & Mild to moderately decreased (20-70\% of normal) \\
\hline $\begin{array}{l}\text { ADAMTS13 } \\
\text { antibody }\end{array}$ & Positive in acquired TTP & Negative \\
\hline Haptoglobin & Markedly decreased & Markedly decreased \\
\hline Schistocytes & ++ to ++++ & None to +++ \\
\hline \multicolumn{3}{|l|}{ Therapeutic response to } \\
\hline TPE & Very good response & Excellent and fast response if treated in early stage \\
\hline Platelet transfusion & Contraindicated & Contraindicated \\
\hline rADAMTS13 & Unknown; expected to be effective in GA-VMTD & Unknown; expected to be very effective \\
\hline
\end{tabular}

AFHF acute fulminant hepatic failure, $A R F / H U S$ acute renal failure/hemolytic uremic syndrome, $A R D S$ acute respiratory distress syndrome, "DIC" disseminated intravascular coagulation of McKay, ECs, endothelial cells, eULVWF/mULVWF endothelial unusually large von Willebrand factor/megakaryocytic ULVWF, LDH lactate dehydrogenase, MAHA/aMAHA microangiopathic hemolytic anemia/atypical MAHA, rADAMTS13 recombinant ADAMTS13, SIRS, systemic inflammatory response syndrome, TMA thrombotic microangiopathy TPE, therapeutic plasma exchange; TTP, thrombotic thrombocytopenic purpura, VMTD vascular microthrombotic disease

syndrome [26]. Quotation marks have been placed on "DIC" to note that it is different from true DIC, which causes fibrin clots composed of fibrin meshes that is seen in acute promyelocytic leukemia (APL).
Hematologists have been puzzled when encountered acquired TTP-like syndrome with negative ADAMTS13 antibody and phenotype of thrombocytopenia and MAHA. This syndrome has occurred with atypical organ 
phenotypes. Such syndromes include the hemolysis, elevated liver enzymes and low platelet (HELLP) syndrome [16], acute respiratory distress syndrome (ARDS) $[2,13,19,20]$, HUS $[3,27,28]$, acute myocardial infraction $[17,29,30]$, acute pancreatitis [21, 31, 32], rhabdomyolysis $[33,34]$, encephalopathy $[35,36]$, viral hemorrhagic fevers $[1,37-40]$ and many others $[2,12-14]$.

\section{TTP vs. TTP-like syndrome}

TTP and TTP-like syndrome are characterized by hematologic phenotypes of VMTD presenting with consumptive thrombocytopenia and MAHA. TTP occurs in two conditions: one is gene mutation-associated VMTD (GA-VMTD) and the other is antibody-associated VMTD (AA-VMTD). GA-VMTD, known as Upshaw-Schulman syndrome, is the result of homozygous or compound heterozygous mutations of ADAMTS13 gene. However, AA-VMTD is autoimmune disease resulting from ADAMTS13 antibody.

In contrast, TTP-like syndrome develops due to endotheliopathy-associated VMTD (EA-VMTD) in critical illnesses such as sepsis and trauma [2, 16, 40-43] as illustrated in Table 1. The pathologic nature of microthrombi, which are composed of platelet and ULVWF complexes, are the same in both TTP and TTP-like syndrome [2-6]. However, the pathophysiological mechanism forming microthrombi appears to be different, and in TTP, their physical configuration in vivo is not clearly defined at this time. In TTP-like syndrome, the organ localization of microthrombi is distinctly different among different organs and within the same organ; perhaps it is due to endothelial heterogeneity and organotropism [3]. To annotate the clinical and organ dysfunction syndromes, occurring as a result of endotheliopathy in critical illnesses, a novel "two-activation theory of the endothelium" has been proposed [1, 2, 26].

\section{Pathogenesis of TTP-like syndrome Thrombocytopenia in critically ill patients (TCIP)}

The earliest suspicion of TTP-like syndrome should come from unexplained thrombocytopenia in the critically ill patient. After exclusion of known causes of thrombocytopenia such as heparin-induced, drug or transfusion-related, consumptive coagulopathy-associated and hypersplenism-caused thrombocytopenia, and others [2], the term TCIP has been used to identify etiology-undetermined thrombocytopenia in critically ill patients. It is particularly well known in infectious diseases, including bacterial, viral, rickettsial, fungal and parasitic sepsis, are associated with TCIP [37-41, 44, 45]. It also occurs in non-infectious illnesses (e.g., severe trauma, cancer, complications of surgery, pregnancy and transplant, and immunologic and collagen vascular diseases) [2, 13, 42, 43, 46, 47].
Recently, significant correlation has been noted between the degree of thrombocytopenia, and severity and outcome of critical illnesses [48, 49]. Severer thrombocytopenia has been associated with systemic inflammatory response syndrome (SIRS) and multiorgan dysfunction syndrome (MODS) [50, 51]. These observations support TCIP is a key participant in the pathogenesis of critical illnesses, leading to VMTD. Now it is clear that TCIP is consumptive thrombocytopenia in the process of DIT in critically ill patients [1-3].

\section{Role of complement activation on the endothelium}

The activation of complement system is one of the pivotal events in innate immune defense mechanism of the host against pathogen. Its protective function for the host is to detect and eliminate invading microorganisms. Opsonization of foreign surfaces by covalently attached C3b fulfills three major functions: cell clearance by phagocytosis; amplification of complement activation by the formation of surface-bound C3 convertase; and assembly of C5 convertases [51]. Following activation of complement system through one of three pathways (classical, alternative, and lectin), cleavage of C5 induces the formation of multi-protein pore complex (C5b-9) (i.e., membrane-attack complex [MAC]), which leads to cell lysis.

However, despite its protective role for the host, when complement system becomes activated in critical illnesses [52, 53], C5b-9 also can attack innocent bystander host endothelial cells (ECs). If CD59 glycoprotein expressed on the endothelial cells [3] is downregulated due to critical illnesses, channel (pore) formation occurs in the endothelial membrane, which leads to endotheliopathy and even endothelial membrane lysis [53, 54]. Although the "imbalanced", "uncontrolled" or "dysregulated" complement activation has been implicated to be the mechanism of atypical HUS, perhaps "unprotected" endothelium due to loss of CD59 protective effect against C5b-9 could be the mechanism leading to endotheliopathy, not only in atypical HUS [53], but also in the critical illnesses.

It is interesting to note that congenital CD59 deficiency due to its gene mutation has been associated with thrombosis and hemolytic anemia [55], which also suggest the close relationship between endothelial CD-59 loss and endotheliopathy. The study of the role of CD59 in the pathogenesis of endotheliopathy is needed.

\section{TTP-like syndrome in the critical illness}

TTP-like syndrome typically occurs in critically ill patients [1, 2, 12-14, 17-21, 25-50, 56]. Inexplicably, in current clinical practice and medical literature, the most of the patients with critical illnesses presenting with VMTD with or without hemorrhagic disorder have been identified as having "DIC" with either compensated (chronic) or 
decompensated (acute) designation [26]. It should be emphasized that "DIC" mimics TTP-like syndrome [1] and chronic DIC is identical to TTP-like syndrome in precipitating factors (i.e., critical illnesses), pathological findings (i.e., hyaline microthrombi), and hematologic features (i.e., thrombocytopenia) [26]. Later, reinterpretation of "DIC" will be separately discussed in more detail.

\section{"Two-activation theory of the endothelium"}

Activated complement system provides a critical and multifaceted defense against infection, but it can be also activated in non-pathogen-induced critical illnesses such as polytrauma, pregnancy, surgery, transplant, autoimmune disease, and cancer [57-61]. Following the activation, complement can clear invading microorganisms by lysis or opsonization [27]. However, on the host side, the complement activation product terminal C5b-9 also could attack the host ECs and cause transmembrane channel formation on the endothelium and induce endotheliopathy. In turn, endotheliopathy triggers multiple molecular events $[1-3,55]$ as presented in Fig. 1.

Critical illnesses are well known to cause an injury to ECs, leading to endotheliopathy and endothelial dysfunction [62, 63]. Now, the evidence shows that complement activation plays the major role in molecular pathogenesis of inflammation and DIT [1-3, $55,58-61,64]$. Based on endotheliopathy that promotes several biomolecular events, the "two-activation theory of

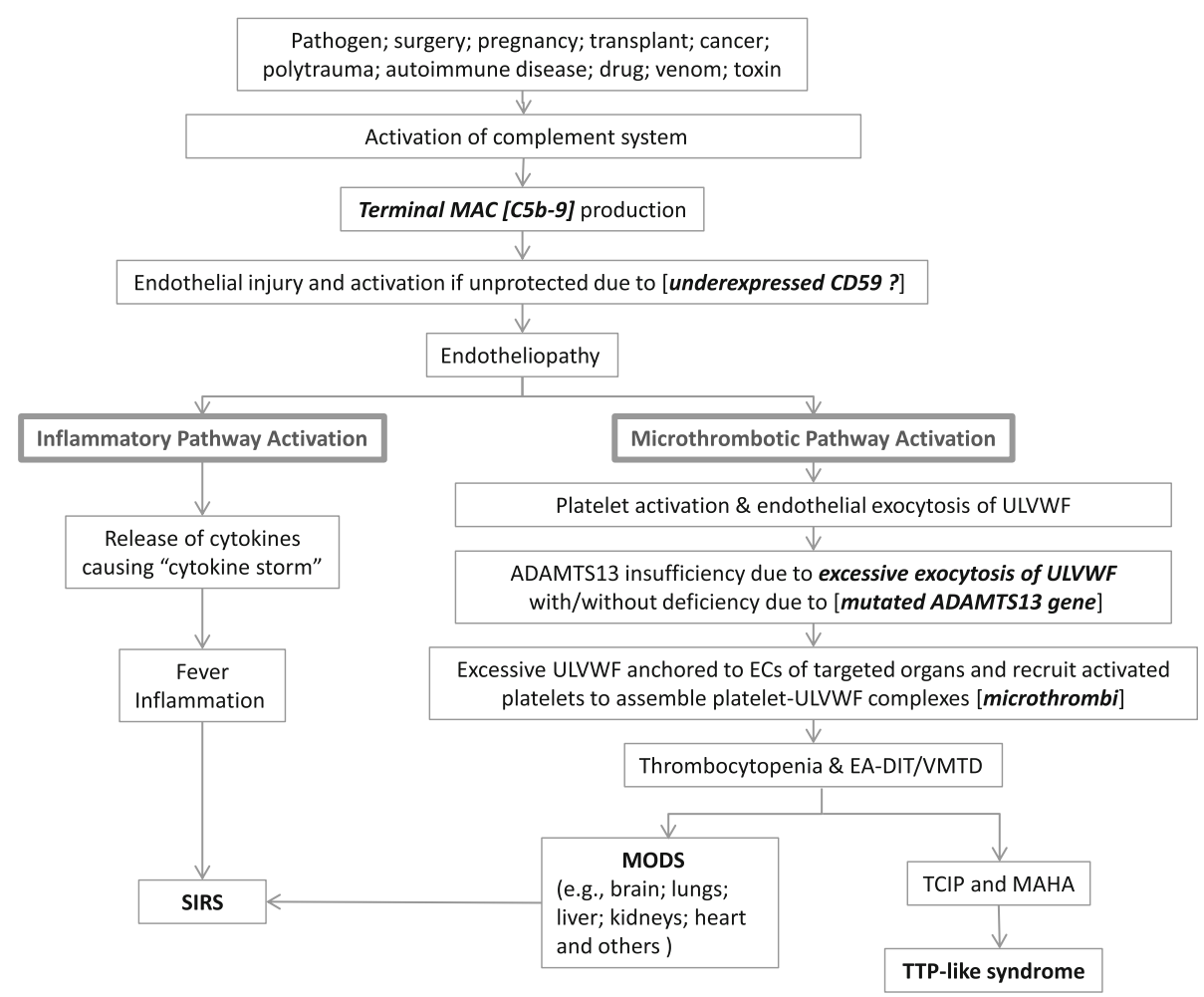

Fig. 1 Molecular pathogenesis of TTP-like syndrome Fig. 1 elaborates "two activation theory of the endothelium", which shows complementinduced endothelial molecular events, leading to endotheliopathy-associated DIT (i.e., TTP-like syndrome) and MODS. The organ phenotype syndrome in MODS includes encephalopathy, ARDS, AFHF, ARF/HUS, MI, Al, pancreatitis, rhabdomyolysis, "DIC", HELLPs, SS, and others. For example, in sepsis complement activation is the initial critical event. Complement activation can occur through one of three different pathways (i.e., classical, alternate and lectin). In addition to lysis of pathogen by terminal product C5b-9, it could induce endotheliopathy to the innocent bystander ECs of the host. C5b-9-induced endotheliopathy is suspected to occur if the endothelium is "unprotected" by CD59. Activated inflammatory pathway provokes inflammation in sepsis, but inflammation could be modest if the number of organ involvement is limited. Activated microthrombotic pathway results in endotheliopathy-associated DIT if the excess of ULWWF develops following endothelial exocytosis as a result of relative insufficiency of ADAMTS13 with/without mild to moderate ADAMTS13 deficiency, which is associated with heterozygous gene mutation or polymorphism of the gene. This theory explains all the manifestations of VMTD as illustrated in the Fig. 1. Abbreviations: AFHF, acute fulminant hepatic failure; $\mathrm{Al}$, adrenal insufficiency; ARDS, acute respiratory distress syndrome; ARF, acute renal failure; "DIC", false disseminated intravascular coagulation; DIT, disseminated intravascular microthrombosis; ECs, endothelial cells; EA-DIT, endotheliopathy-associated DIT; HELLPS, hemolysis, elevated liver enzymes, and low platelet syndrome; HUS, hemolytic uremic syndrome; Ml, myocardial infarction; MODS, multi-organ dysfunction syndrome; MAHA, microangiopathic hemolytic anemia; SIRS, systemic inflammatory response syndrome; SS, stroke syndrome; TCIP, thrombocytopenia in critically ill patient; TTP, thrombotic thrombocytopenic purpura; ULWWF, unusually large von Willebrand factor; VMTD, vascular microthrombotic disease 
the endothelium" is proposed and illustrated in Fig. 1 $[1,2]$. Endotheliopathy triggers the activation of two independent endothelial pathways (i.e., inflammatory and microthrombotic). In short, two important molecular events are: 1) release of inflammatory cytokines (e.g., interleukin [IL]-1, IL-6, tumor necrosis factor- $\alpha$, and others) $[63,65,66]$, and 2) activation of the platelet [67] and endothelial exocytosis of ULVWF $[68,69]$. The former initiates inflammation through "activation of inflammatory pathway", and the latter mediates microthrombogenesis via "activation of microthrombotic pathway" $[1-3,26]$ as shown in Fig. 1.

In endotheliopathy, microthrombogenesis is a process, in which long elongated ULVWF strings are anchored to ECs after release from Weibel-Palade bodies and recruit platelets, promoting the formation of platelet-ULVWF complexes $[5,6,70]$. These microthrombi strings are the pathologic complexes formed, perhaps under the shear stress of blood flow, leading to endotheliopathy-associated DIT and hematologic features of TTP-like syndrome $[2,4]$.

\section{Microthrombogenesis in VMTD \\ Megakaryocytic ULVWF(mULVWF) and endothelial ULVWF(eULVWF)}

Two kinds of ULVWF are synthesized in two different sites (i.e., megakaryocytes and ECs) as shown in Table $2[4,71]$. Megakaryocytic ULVWF (mULVWF) are released normally into circulation as platelet-adherent form and stored in $\alpha$ granules of the platelet. But endothelial ULVWF (eULVWF) are produced in ECs and stored in Weibel-Palade bodies to be available as endothelium-adherent form following release from ECs to initiate normal hemostasis in vascular injury $[4,6,72]$.
Although the differences in structure and function between mULVWF and eULVWF are unknown at this time, it appears two different ULVWF multimers from different origin may have different functions [73, 74]. Microthrombogenesis of TTP occurs in microcirculation $[4,75]$ due to hyperactivity of circulating MULVWF in hereditary and antibody-associated ADAMTS13 deficiency. However, TTP-like syndrome is likely associated with relative insufficiency of ADAMTS13 as a result of excessive exocytosis of eULVWF in endotheliopathy [2]. In TTP, mULVWF multimers might react with platelets and assemble microthrombi in the microvasculature in situ under the shear stress, but in TTP-like syndrome eULVWF strings are anchored to ECs and get decorated with platelets to form microthrombi strings $[5,6,70]$.

In severe sepsis, decreased ADAMTS13 activity is correlated with greater adhesion capacity of ULVWF and higher degree of thrombocytopenia as well as severity of critical illnesses and organ dysfunction [76]. Decreased ADAMTS13 activity in some patients with TTP-like syndrome also suggests underling partial ADAMTS13 deficiency could exist as well. In addition to endothelial exocytosis of ULVWF, partial ADAMTS13 deficiency associated with polymorphism or heterozygous mutation of the gene could contribute to the onset and degree of severity of TTP-like syndrome [77-80].

Both ULVWF lodged in capillaries and ULVWF anchored to ECs are rapidly cleaved by ADAMTS13 in vitro $[4,6,72]$. This observation is certainly consistent with the benefit of TPE for TTP due to ADAMTS13 deficiency and TTP-like syndrome with its insufficiency.

Table 2 Characteristics of two different ULWWF multimers

\begin{tabular}{lll}
\hline & mULWW multimers & eULWWF multimers \\
\hline Synthesized in & Megakaryocytes & Endothelial cells \\
Stored in & a granules of platelets & Weibel-Palade bodies of ECs \\
Primary distribution at release & In circulation & On the membrane of ECs \\
Availability & In microcirculation & At ECs following endothelial exocytosis \\
Exposure to ADAMTS13 & As platelet-adherent form & As ECs-adherent form \\
Interaction with platelets causing & Platelet aggregation and adhesion & Platelet-ULWF strings \\
Localization of platelet-ULWWF & Arteriolar and capillary lumens lodged as microthrombi & Endothelial membrane-anchored as microthrombi \\
complexes & in situ & strings \\
Example of leading its activity & ADAMTS13 autoantibody & Sepsis-induced endotheliopathy \\
Endotheliopathic lesion & Microthrombotic microangiopathy & Microthrombotic angiopathy \\
Hematologic manifestation & Thrombocytopenia and MAHA & Thrombocytopenia and MAHA/aMAHA \\
Associated inflammation & None to minimal (?) & Mild to severe \\
Associated clinical syndrome & TTP & TTP-like syndrome \\
\hline
\end{tabular}

ECs endothelial cells, eULVWF/mULVWF endothelial unusually large von Willebrand factor/megakaryocytic ULVWF, MAHA/aMAHA microangiopathic hemolytic anemia/atypical MAHA, TTP thrombotic thrombocytopenic purpura 


\section{Dissimilarity between TTP and TTP-like syndrome}

The dissimilar pathogenesis and different phenotypic characteristics between TTP and TTP-like syndrome are summarized in Table 1. It is hypothesized that microthrombogenesis in acquired TTP is caused by hyperactivity of mULVWF due to anti-ADAMTS13 antibody and occurs in the microvasculature in situ. On the other hand, microthrombogenesis in TTP-like syndrome is triggered by excessive exocytosis of eULVWF from ECs and occurs in the endothelial membrane. In both cases, deficient and or insufficient ADAMTS13 could not handle the excess of ULVWF.

This slightly different microthrombogenesis could lead to different organ localization and configuration of microthrombi, but still produce the same hematologic phenotype of VMTD. In TTP, microthrombi formed in the microvasculature become lodged within arterioles and capillaries of the brain and kidneys [4], which condition can be called "microvascular" microthrombosis. In TTP-like syndrome, it takes place on the smaller and larger vasculatures [80-83] of various organs depending upon endothelial heterogeneity that determines organ localization [83-85], which condition could be called "vascular" microthrombosis. We know more about endothelial microthrombogenesis in TTP-like syndrome, but do not know how microthrombogenesis in TTP occurs in microcirculation in vivo other than that it might be promoted under the condition of shear stress due to blood flow.

Without the understanding the endothelial molecular pathogenesis of TTP-like syndrome, clinicians have thought the atypical feature of different organ involvement in TTP-like syndrome is just a variant of TTP. In reality, different organ phenotypic TTP-like syndromes occur as a result of endothelial heterogeneity caused by genetic variables [3, 83-85] through endowed molecules in ECs (e.g., CD59 and Gb3 in HUS) [3, 86]. For examples, extra renal manifestations of Shiga toxin-producing E. coli-HUS (STEC-HUS) represent expression of endothelial heterogeneity caused by endowed molecules, localizing in the brain with encephalopathy, heart with myocardial infarction, pancreas with pancreatitis, and others [3].

\section{Reinterpretation of "DIC"}

"DIC" has been the most intriguing disease among all the human diseases because of its deadly nature and conundrums as listed follows [26]:

- No clearly defined clinical and pathological diagnostic criteria are available.

- Not a single test or set of the tests can confirm and establish the diagnosis.
- Unexplained bleeding disorders such as viral hemorrhagic fevers are often blamed to it without foundation.

- Establishing the diagnostic application has been very subjective among investigators.

- The scoring system for the diagnosis is imprecise, confusing and subjective.

- The pathogenesis (i.e., tissue factor [TF]-FVIIa activated coagulopathy) has never been proven.

- Not a single treatment has been clearly proven to be effective.

- No therapeutic benefit has occurred even after numerous clinical trials.

Only consistent clinical, pathologic and hematologic features are:

- It occurs in critical illnesses (e.g., sepsis) and APL, but with different phenotypes.

- Clinical features are VMTD (i.e., DIT).

- Pathologic features are arteriolar and capillary hyaline microthrombi.

- Hematologic features are thrombocytopenia and MAHA.

True DIC (e.g., consumption coagulopathy), which occurs in APL $[87,88]$, is a coagulation (hemorrhagic) disorder, developing due to activation of TF-FVIIa complex-initiated coagulation cascade. In APL, TF is strongly expressed in leukemic promyelocytic cells. TF triggers fibrinogenesis via activation of FVII. On the other hand, "DIC", which occurs in critical illnesses, has also been named as DIC based on the same TF-initiated coagulation (thrombotic) disorder [89, 90]. However, the clinical and hematologic features are very different between APL and critical illnesses. Instead, the clinical, pathological and hematological features of "DIC" are identical to endotheliopathy-associated DIT [1, 2], which is microthrombotic disorder. The differences between "DIC" (i.e., microthrombi) and true DIC (i.e., fibrin clots) are summarized in Table 3.

\section{Pathologic coagulation (DVT) vs. microthrombogenesis (DIT)} A very important question is: "where does "DIC" belong to DVT, DIT, or true DIC of APL?" Is DIT conveniently ignored from the standpoint of hemostatic disorder?

In clinical medicine, the physiological mechanism of hemostasis and pathological mechanism of thrombosis has been considered to be the result of the same coagulation process with two different outcomes due to the different circumstance of the injury. Hemostasis is a normal protective physiological process to stop bleeding following external bodily injury, but pathologic thrombosis is the result of normal hemostatic process within 
Table 3 Hematologic and Clinical Characteristics of endotheliopathy-associated DIT and true DIC

\begin{tabular}{|c|c|c|}
\hline & EA-DITNMTD and "DIC" of McKay & True DIC \\
\hline Example & TTP-like syndrome & APL \\
\hline Nature of the clots & "Microthrombi strings" made of platelet-ULWWF complexes & "Fibrin clots" made of fibrin meshes \\
\hline Mechanism of the genesis & Intravascular microthrombogenesis & Intravascular fibrinogenesis \\
\hline Inciting causes/events & $\begin{array}{l}\text { Infection; surgery; pregnancy; transplant; cancer; drug; } \\
\text { toxin, leading to edotheliopathy }\end{array}$ & APL, leading to TF expression \\
\hline Hematological manifestation & Microthrombotic disorder & Hemorrhagic disorder \\
\hline \multicolumn{3}{|l|}{ Pathogenesis } \\
\hline Mechanism & Activation of microthrombotic pathway & Activation of TF-initiated coagulation cascade \\
\hline Site of activation & Intravascular membrane of ECs & In circulation \\
\hline Thrombopathic result & Intravascular hemostasis of ULVWF path & Consumption of fibrinogen, FV and FVIII \\
\hline Effect on the involved organ & Hypoxic organ dysfunction & Generalized bleeding tendency \\
\hline \multicolumn{3}{|l|}{ Coagulation tests } \\
\hline Fibrinogen & Normal & Decreased \\
\hline PT; aPTT; Tा & Normal & Prolonged \\
\hline FVIII activity & Normal or markedly increased & Markedly decreased \\
\hline Thrombocytopenia & Mild to moderately severe & Not consumed but decreased due to APL \\
\hline Associated clinical syndrome & MODS; cytokine storm; SIRS & Hemorrhagic syndrome \\
\hline \multicolumn{3}{|l|}{ Associate hematologic features } \\
\hline Schistocytes & Often present & Absent \\
\hline MAHA/aMAHA & Almost always present & Does not occur \\
\hline Hepatic coagulopathy & Common & Does not occur \\
\hline Incidence in clinical practice & Very common & Extremely rare \\
\hline \multicolumn{3}{|l|}{ Management } \\
\hline Platelet transfusion & Contraindicated & May be used if needed for APL \\
\hline Treatment & TPE; rADAMTS13 (expected to be very effective) & Treat underlying pathology (e.g., ATRA in APL) \\
\hline
\end{tabular}

intravascular space following intravascular injury [91]. Following TF-activated coagulation cascade, the nature of formed intravascular thrombus (e.g., deep vein thrombosis [DVT] and "DIC") has been presumed to be the same nature to the hemostatic plug (e.g., blood clots after an injury) [90, 91]. If this is the case, how can we explain that DVT is made of macrothrombus but "DIC" is made of microthrombi? Coagulation scientists have not answered this thought provoking question yet.

Intravascular microthrombosis occurring in "DIC" has been interpreted to be a pathological coagulation disorder mediated through TF-initiated FVII activation $[90,91]$. This conception has been strengthened on the following grounds: 1) the term "DIC", coined by Donald McKay [91, 92], clearly implied that it is a coagulation disorder and this assumption has been accepted by clinicians and coagulation scientists without laboratory and molecular verification, and 2) unlike DIT (i.e., TTP-like syndrome), "DIC" sometimes has occurred with severe hemorrhagic disorder associated with abnormal coagulation profile of prolonged prothrombin time, activated partial thromboplastin time, hypofibinogenemia, and increased fibrin degradation products, which is consistent with consumption of coagulation factors following TF-initiated coagulation cascade. But then, there is chronic "DIC", which is exactly the same to the feature of endotheliopathy-associated DIT.

However, this abnormal coagulation profile in acute "DIC" is non-specific even though the prevailing interpretation has blamed it to the consumption of coagulation factors in "DIC". This author differs from this assumption, which will be further discussed later, along with hepatic coagulopathy.

The concept of microthrombogenesis clearly supports that "microthrombi" in DIT are exclusively composed of platelet-ULVWF complexes [1, 2, 4-6]. In 
contrast, the ironclad concept of "microthrombi" in "DIC" has been "micro blood clots" made of fibrin clots with participation of platelets via TF-initiated coagulation cascade [89-91].

In fact, chronic "DIC" and endotheliopathy-associated DIT (i.e., TTP-like syndrome) are exactly the same in their underlying risk factors, pathologic and phenotypic presentation. First, clinically both disorders almost always occur in critical illnesses; second, their pathology is characterized by arteriolar and capillary hyaline microthrombi with variable fibroblastic proliferation [4, 92]; third, hematologic features are consumptive thrombocytopenia and MAHA. Thus, chronic "DIC" and endotheliopathy-associated DIT are one disease. Until now "DIC" has been incorrectly ascribed to pathological coagulation disorder initiated by TF-induced coagulation [89, 93-97]. This misconception of "DIC" has contributed to many unexplainable mysterious features of "DIC" to date. Now, it is clear that macrothrombus of DVT and microthrombi of DIT/ "DIC" occur in intravascular injury due to dissimilar hemostatic pathogenesis.

\section{"DIC" perplexity discussed}

Table 3 is self-explanatory showing the difference in hematologic and clinical characteristics between endotheliopaathy-associated DIT (i.e., TTP-like syndrome, including McKay's "DIC") and true DIC of fibrin clots occurring in APL. In contrast to "DIC"(i.e., false DIC), the predominant feature of true DIC (i.e., in APL) is always hemorrhagic disorder without microvascular thrombosis, MAHA and MODS [87, 98-101]. In regard to "DIC" mystery, a few more comments are appropriate.

First, the International Society on Thrombosis and Hemostasis (ISTH) has introduced the "DIC" scoring system to better establish the diagnosis of "DIC" [102]. It has not been used as a primary diagnostic tool, but has been applied to confirm the diagnosis using hematologic parameters only after predetermined as "DIC" with a clinical disorder known to cause "DIC". The scoring system has shown low specificity [102]. It should be emphasized that no single laboratory test or set of tests is sensitive or specific enough to allow a definitive diagnosis of "DIC" [103]. In most cases, the diagnosis is based on the combination of results of non-specific abnormal coagulation profile with a clinical condition known to be associated with "DIC" [104].

Second, coagulation scientists put their efforts to support the role of TF in "DIC", by proposing TF encryption/decryption theory [105], thiol path TF regulation theory [106], TF transfer hypothesis [107], and inflammation and coagulation interaction theory [108-111], which are all still controversial and have not proven the role of TF in "DIC". Furthermore, the negligible amount of in vivo TF, even available, cannot explain the "DIC" presenting with extensive vascular microthrombosis and MODS.

Third, the abnormal coagulation profile, showing prolonged prothrombin time and activated partial thromboplastin time, hypofibinogenemia, and increased fibrin degradation products, is non-specific, and cannot affirm the diagnosis of true DIC. Additionally, this profile oddly develops only in some patients with "DIC". Therefore, the "chronic/compensated/covert" concept [102, 112, 113], including "low grade DIC", has been introduced if the coagulation profile is normal or mildly abnormal in "DIC". This description also cannot explain inexplicably extensive microthrombosis in the absence of depleted coagulation factors.

Fourth, numerous randomized clinical trials (e.g., TF pathway inhibitor, activated protein $\mathrm{C}$, anticoagulant, anti-inflammatory cytokines, and others) to modulate septic response to infection, which pathogenesis is firmly based on interaction theory between inflammation and TF-initiated coagulation, have not been successful to improve the survival in sepsis $[114,115]$.

It is no wonder, after extensive laboratory studies and clinical trials, why a specific diagnostic test(s) has not been established and no effective treatment discovered for "DIC" after more than half century since DIC was coined in 1950 [91, 92]. The simple answer is that the thesis of TF-initiated pathogenesis of "DIC" has been erroneous.

\section{Acute "DIC" is due to DIT-associated hepatic coagulopathy}

One remaining, very pertinent question is: "what is the correct diagnosis for acute/decompensated/overt "DIC" that is associated with abnormal coagulation profile?" The answer is clear since "DIC" is often associated with hepatic diseases $[1,15,116-120]$. In endotheliopathy-associated DIT, hepatic coagulopathy could occur as a phenotype of acute fulminant hepatic failure or acute hepatic necrosis as seen in critical illnesses [15, 90, 116-120]. The pathogenesis unknown hepato-renal syndrome [121-123] and hepatic encephalopathy $[15,121]$ are very much consistent with endotheliopathy-associated DIT similar to "DIC" syndrome. Thus, acute "DIC" is hepatic coagulopathy occurring in endotheliopathy-associated DIT.

Indeed, the medical literature is replete with DIT, "DIC" and/or hepatic failure, occurring in association with HELLP syndrome, HUS, acute necrotizing pancreatitis, purpura fulminans, rhabdomyolysis, acute respiratory distress syndrome, viral hemorrhagic fevers as well as hepato-renal syndrome and hepatic encephalopathy. In retrospect, when clinical phenotype of acute fulminant hepatic failure or acute hepatic necrosis presents with thrombocytopenia and coagulopathy, 
Enthotheliopathy-associated DIT (i.e., TTP-like syndrome) should be suspected rather than the diagnosis of acute "DIC" [26]. Indeed, hepatic coagulopathy occurring in DIT is a life-threatening thrombo-hemorrhagic syndrome without correct diagnosis [26].

\section{Differential diagnosis of true DIC and TTP-like syndrome}

In differentiating true DIC (e.g., APL) from DIT with hepatic coagulopathy, the most reliable test is the assay of coagulation factors $[1,2,87,99,124,125]$ (Table 4). In true DIC, FVIII and FV are markedly decreased due to their consumption and inactivation, but, in DIT with hepatic coagulopathy (i.e., acute "DIC"), FVIII is normal or more likely markedly increased and FVII is markedly decreased. The increase of FVIII in hepatic coagulopathy is likely due to endothelial exocytosis of ULVWF, in which some of ULVWF are cleaved by ADAMTS13 to smaller VWF multimers and released into circulation to bind FVIII and protect it from degradation. A suggested guideline for laboratory tests is summarized in Table 4 to aid in the differential diagnosis among complicated thrombopathies and coagulopathies $[1,2]$.

\section{Hope for the future in the treatment}

VMTD presenting with both TTP and TTP-like syndrome has responded well to TPE if the treatment is initiated in the earliest possible stage [11-13, 20, 41, 42]. In medical literature, there is a plethora of case reports of successful treatment with TPE for atypical TTP and TTP-like syndrome. Once the disease progresses to the point of irreversible organ dysfunction due to tissue hypoxia, recovery is unlikely to occur in TTP-like syndrome [13]. This is particularly true in ARDS [20], encephalopathy in HUS [126], and adrenal insufficiency in sepsis (i.e., septic shock) [127].

High mortality associated with "DIC" in critically ill patients could have been related to platelet transfusions as well as masked hepatic coagulopathy and heparin treatment. The platelet transfusion is contraindicated because it aggravates on-going microthrombogenesis, and heparin treatment increases hemorrhage in hepatic coagulopathy. TPE is the treatment of choice for DIT at this time. Fresh frozen plasma or recombinant FVIIa [128] to replace the lowest FVII might have been beneficial for severe hemorrhage in hepatic coagulopathy associated with VMTD.

Table 4 Hematologic differential diagnoses among thrombopathies and coagulopathies

\begin{tabular}{|c|c|c|c|c|}
\hline & $\begin{array}{l}\text { TTP \& TTP-like } \\
\text { syndrome (DIT) }\end{array}$ & $\begin{array}{l}\text { TTP-like syndrome (DIT) associated } \\
\text { with HC (e.g., sepsis) equal to acute "DIC" }\end{array}$ & DIC (e.g., APL) & PF (e.g., amyloidosis) \\
\hline Thrombocytopenia & Always present & Always present & $\begin{array}{l}\text { Present due to APL, but not due to } \\
\text { consumption (?) }\end{array}$ & Not present \\
\hline MAHA/aMAHA & Always present & Always present & Do not occur & Not present \\
\hline Fibrinogen & Normal & Decreased & Always decreased & Always decreased \\
\hline Factor VIII & Normal & Normal or increased & Markedly decreased & Decreased \\
\hline Factor V & Normal & Decreased & Decreased & $\begin{array}{l}\text { Normal or } \\
\text { decreased }\end{array}$ \\
\hline Factor X & Normal & Decreased & Usually normal & Normal (?) \\
\hline Factor VII & Normal & Markedly decreased & Normal & Normal \\
\hline Factor IX & Normal & Decreased & Normal & Normal \\
\hline FDP & Normal & $?$ & Positive & Strongly positive \\
\hline Prothrombin time & Normal & Prolonged & Prolonged & Prolonged \\
\hline $\begin{array}{l}\text { Activated partial } \\
\text { thromboplastin } \\
\text { time }\end{array}$ & Normal & Prolonged & Prolonged & Prolonged \\
\hline Thrombin time & Normal & Prolonged & Prolonged & Prolonged \\
\hline Thrombosis form & Microthrombi & Microthrombi & Friable fibrin clots (meshes) & Absent \\
\hline $\begin{array}{l}\text { Bleeding: } \\
\text { Character } \\
\text { Treatment }\end{array}$ & $\begin{array}{l}\text { Petechiae; } \\
\text { Usually no need of } \\
\text { treatment }\end{array}$ & $\begin{array}{l}\text { May cause serious bleeding; } \\
\text { Controllable with FFP \& rFVlla }\end{array}$ & $\begin{array}{l}\text { Common, serious bleeding; } \\
\text { Abrogated with ATRA \& } \\
\text { chemotherapy }\end{array}$ & $\begin{array}{l}\text { Slow \& persistent } \\
\text { bleeding; } \\
\text { Treatable with AFA }\end{array}$ \\
\hline $\begin{array}{l}\text { Hypoxic organ } \\
\text { dysfunction } \\
\text { (MODS) }\end{array}$ & Present & Present & Not present & Not present \\
\hline Platelet transfusion & Contraindicated & Contraindicated & May be used for APL & Not needed \\
\hline
\end{tabular}

AFA anti-fibrinolytic agent, ATRA all-trans retinoic acid, "DIC" false disseminated intravascular coagulation, DIT disseminated intravascular microthrombosis, FDP fibrin degradation products, FFP fresh frozen plasma; $H C$ hepatic coagulopathy; MAHA/aMAHA microangiopathic hemolytic anemia/atypical MAHA, $P F$ primary fibrinolysis, TTP thrombotic thrombocytopenic purpura 
Theoretically, two very promising targeted therapeutic approaches for TTP-like syndrome are 1) anti-complement therapy such as eculizumab and recombinant CD59 to inhibit the first leg of the pathogenesis based on "two-activation theory of the endothelium" [3, 129-131] and 2) anti-microthrombotic therapy such as recombinant ADAMTS13 to correct or modify the second leg of the endothelial pathogenesis [3]. Indeed, eculizumab has shown promising results [129, 130]. However, anti-complement therapy should be explored with an extreme care since it could cause catastrophic harm in the septic patient by aggravating the ongoing process of sepsis and septic shock. Currently, recombinant ADAMTS13 is being investigated for the treatment of hereditary TTP. Since it has shown to cleave eULVWF $[4,6,69]$, controlled clinical trials should be initiated for TTP-like syndrome as soon as possible. If it is effective, recombinant ADAMTS13 could save so many lives, especially in the critical care medicine, obstetrics, surgery, transplant and more.

\section{Conclusion}

TTP and TTP-like syndrome are two different diseases caused by dissimilar pathogenesis although their underlying pathologic feature of DIT and hematologic phenotype are similar. TTP is intravascular microthrombotic disease due to ADAMTS13 deficiency, but TTP-like syndrome is hemostatic disease associated with endotheliopathy in critical illnesses. It is essential to recognize TTP-like syndrome as a distinct disease entity, which working diagnostic criteria is summarized in Table 5. These criteria would benefit the patient through earlier unmasking of the diagnosis and life-saving TPE when presented with atypical organ phenotypic syndromes. Certainly, "two activation theory of the endothelium" has been able to clarify many unresolved issues of thrombotic microangiopathy. Among them are TTP, HUS, TTP-like syndrome, MODS, "DIC" and combined organ dysfunction syndrome with hepatic coagulopathy.

Both activation of complement through C5b-9 in critical illnesses and microthrombogenesis with participation of the platelet and ULVWF have unequivocally supported the crucial role of endotheliopathy in the pathogenesis of TTP-like syndrome. The role of endothelial protectin CD59 and C5b-9 should be evaluated to further support the endothelial molecular pathogenesis in TTP-like syndrome [131]. The future therapeutic modalities should be explored with anti-complement therapy and anti-microthrombotic therapy. This author believes anti-microthrombotic therapy is safer option.

Lastly, the designation of the term VMTD is very appropriate not only for TTP and TTP-like syndrome, but also to include hereditary focal, multifocal and localized microthrombotic diseases, and acquired microthrombotic disorders such as stroke syndromes, cardiac
Table 5 Proposed working diagnostic criteria for TTP-like syndrome

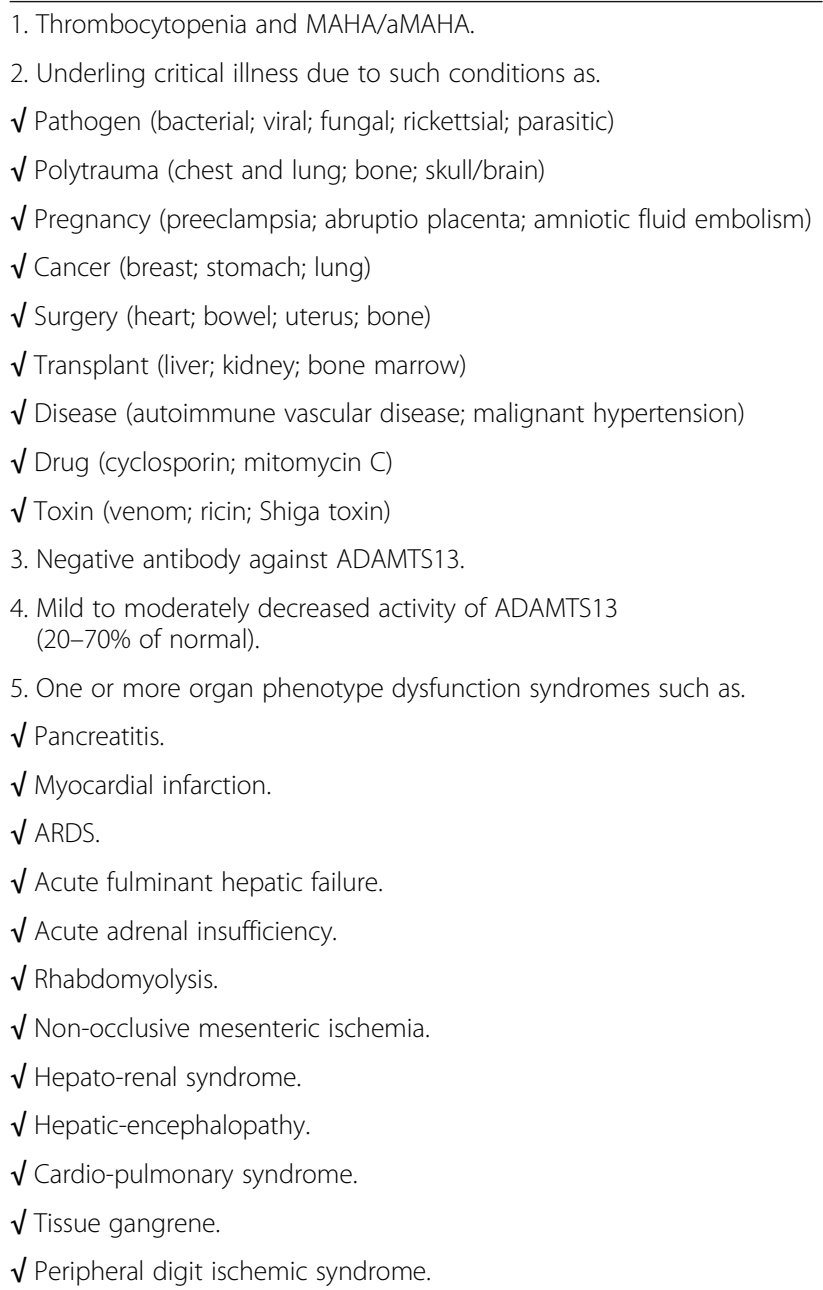

+ Encephalopathy and ARF are common in both TTP and TTP-like syndrome $A R D S$ acute respiratory distress syndrome, TTP thrombotic thrombocytopenic purpura

angina, and coronary procedure-associated transient microthrombotic syndrome. The recognition of the term VMTD would further assist in the understanding of endothelial physiology and identifying of endothelial pathophysiology in many human diseases, especially in hemostasis and hemostatic disorders.

\footnotetext{
Abbreviations

ADAMTS13: A disintegrin and metalloproteinase with a thrombospondin type 1 motif, member 13; AFA: Anti-fibrinolytic agent; AFHF: Acute fulminant hepatic failure; Al: Adrenal insufficiency; APL: Acute promyelocytic leukemia; aPTT: Activated partial thromboplastin time; ARDS: Acute respiratory distress syndrome; rADAMTS13: Recombinant ADAMTS13; ARF: Acute renal failure; ATRA: All-trans retinoic acid; DIC: Disseminated intravascular coagulation; "DIC" : false disseminated intravascular coagulation; DIT: Disseminated intravascular thrombosis; ECs: Endothelial cells; FDP: Fibrin degradation products; FFP: Fresh frozen plasma; FVIla: Activated factor VII; FVIII: Factor VIII; HC: Hepatic coagulopathy; IL: Interleukin; HELLPs: Hemolysis elevated liver enzymes and low platelet syndrome; HUS: Hemolytic uremic syndrome; LDH: Lactate dehydrogenase; MAC: Membrane attack complex; MI: Myocardial infarction; MAHA: Microangiopathic hemolytic anemia; aMAHA: Atypical MAHA; MODS: Multi-organ dysfunction syndrome;
} 
PF: Purpura fulminans; PT: Prothrombin time; SIRS: Systemic inflammatory response syndrome; SS: Stroke syndrome; STEC: Shiga toxin producing E. coli; TCIP: Thrombocytopenia in critically ill patient; TF: Tissue factor; TPE: Therapeutic plasma exchange; TTP: Thrombotic thrombocytopenic purpura; vWF: von Willebrand factor; ULVWF: Unusually large von Willebrand factor multimers; eULWW: Endothelial ULWWF; mULVWF: Megakaryocytic ULWWF; VMTD: Vascular microthrombotic disease; AA-VMTD: antibody associated VMTD; EA-VMTD: Endotheliopathy associated VMTD; GAVMTD: Gene mutation associated VMTD

\section{Availability of data and materials}

"Data sharing not applicable to this article as no datasets were generated or analysed during the current study. If you do not wish to publicly share your data, please write: "Please contact author for data requests."

\section{Authors' contributions}

Contributed $100 \%$ by the corresponding author. The authors read and approved the final manuscript.

\section{Authors' information}

Board certified hematologist and hematopathologist, retired professor of medicine in the University of California Irvine School of Medicine, and retired professor of medicine in the Wright State University of School of Medicine.

\section{Ethics approval and consent to participate}

Not applicable.

\section{Consent for publication}

Not applicable.

\section{Competing interests}

The author declares that he have no competing interests.

\section{Publisher's Note}

Springer Nature remains neutral with regard to jurisdictional claims in published maps and institutional affiliations.

Received: 15 March 2018 Accepted: 7 June 2018

Published online: 11 August 2018

\section{References}

1. Chang JC. A Thought on Possible Pathogenesis of Ebola Viral Hemorrhagic Disease and Potential Treatments: Could it Be Thrombotic

Thrombocytopenic Purpura-like Syndrome? Ther Apher Dial. 2015;20:93-8.

2. Chang JC. Thrombocytopenia in critically ill patients due to vascular microthrombotic disease: pathogenesis based on "two activation theory of the endothelium". Vascul Dis Ther. 2017;2:1-7.

3. Chang JC. Molecular pathogenesis of STEC-HUS caused by endothelial heterogeneity and unprotected complement activation, leading to endotheliopathy and impaired ADAMTS13 activity: based on two-activation theory of the endothelium and vascular microthrombotic disease. Nephrol Renal Dis. 2017;2:1-8.

4. Tsai HM. Pathophysiology of thrombotic thrombocytopenic purpura. Int J Hematol. 2010;91:1-19.

5. Chauhan AK, Goerge T, Schneider SW, Wagner DD. Formation of platelet strings and microthrombi in the presence of ADAMTS-13 inhibitor does not require P-selectin or beta3 integrin. J Thromb Haemost. 2007:5:583-9.

6. Dong JF, Moake JL, Nolasco L, et al. ADAMTS-13 rapidly cleaves newly secreted ultralarge von Willebrand factor multimers on the endothelial surface under flowing conditions. Blood. 2002;100:4033-9.

7. Moschcowitz E. An acute febrile pleiochromic anemia with hyaline thrombosis of the terminal arterioles and capillaries: an undescribed disease. Arch Intern Med. 1925;36:89-93.

8. Singer K, Bornstein FP, Wile SA. Thrombotic thrombocytopenic purpura; hemorrhagic diathesis with generalized platelet thromboses. Blood. 1947;2:542-54

9. Sonneveld MA, de Maat MP, Portegies ML, et al. Low ADAMTS13 activity is associated with an increased risk of ischemic stroke. Blood. 2015;126:2739-46.

10. Akyol O, Akyol S, Chen CH. Update on ADAMTS13 and WWF in cardiovascular and hematological disorders. Clin Chim Acta. 2016;463:109-18.
11. Chang JC, Newman RS. Redefining the syndromes of thrombotic microangiopathy. Ther Apher Dial. 2004;8:73-4.

12. Chang JC. The understanding of thrombotic thrombocytopenic purpura: Dyadic, triadic, pentadic, and other manifestations. J Clin Apher. 2004;19:2-4.

13. Chang JC, Kathula SK. Various clinical manifestations in patients with thrombotic microangiopathy. J Investig Med. 2002;50:201-6.

14. Sarode R. Atypical presentations of thrombotic thrombocytopenic purpura: a review. J Clin Apher. 2009;24:47-52.

15. Panackel C, Thomas R, Sebastian B, Mathai SK. Recent advances in management of acute liver failure. Indian J Crit Care Med. 2015;19:27-33.

16. Rath W, Faridi A, Dudenhausen JW. HELLP syndrome. J Perinat Med. 2000; 28:249-60.

17. Wahla AS, Ruiz J, Noureddine N, Upadhya B, Sane DC, Owen J. Myocardial infarction in thrombotic thrombocytopenic purpura: a single-center experience and literature review. Eur J Haematol. 2008;81:311-6.

18. Hawkins BM, Abu-Fadel M, Vesely SK, George JN. Clinical cardiac involvement in thrombotic thrombocytopenic purpura: a systematic review. Transfusion. 2008:48:382-92.

19. Bone RC, Henry JE, Petterson J, et al. Respiratory dysfunction in thrombotic thrombocytopenic purpura. Am J Med. 1978;65:262-70.

20. Chang JC, Aly ES. Acute respiratory distress syndrome as a major clinical manifestation of thrombotic thrombocytopenic purpura. Am J Med Sci. 2001;321:124-8.

21. Swisher KK, Doan JT, Vesely SK, et al. Pancreatitis preceding acute episodes of thrombotic thrombocytopenic purpura-hemolytic uremic syndrome: report of five patients with a systematic review of published reports. Haematologica. 2007;92:936-43.

22. Moake JL, Rudy CK, Troll JH, et al. Unusually large plasma factor VIII:von Willebrand factor multimers in chronic relapsing thrombotic thrombocytopenic purpura. N Engl J Med. 1982;307:1432-5.

23. Furlan $M$, Robles $R$, Lämmle B. Partial purification and characterization of a protease from human plasma cleaving von Willebrand factor to fragments produced by in vivo proteolysis. Blood. 1996;87:4223-34.

24. Tsai HM. Physiologic cleavage of von Willebrand factor by a plasma protease is dependent on its conformation and requires calcium ion. Blood. 1996;87:4235-4.

25. George JN. How I treat patients with thrombotic thrombocytopenic purpura-hemolytic uremic syndrome. Blood. 2000;96:1223-9.

26. Chang JC. Disseminated intravascular coagulation: is it fact or fancy? Blood Coagul Fibrinolysis. 2018;29:3030-7.

27. Ray PE, Liu XH. Pathogenesis of Shiga toxin-induced hemolytic uremic syndrome. Pediatr Nephrol. 2001;16:823-39.

28. Zhang K, Lu Y, Harley KT, Tran MH. Atypical Hemolytic Uremic Syndrome: A Brief Review. Hematol Rep. 2017;9:7053.

29. Takimoto T, Nakao M, Nakajo T, Chinen Y, Kuroda J, Taniwaki M. Acute myocardial infarction as the initial thrombotic event of thrombotic thrombocytopenic purpura. Blood Coagul Fibrinolysis. 2016;27:948-51.

30. Atreya AR, Arora S, Sivalingam SK, Giugliano GR. ST segment elevation myocardial infarction as a presenting feature of thrombotic thrombocytopenic purpura. J Cardiovasc Dis Res. 2012;3:167-9.

31. McDonald V, Laffan M, Benjamin S, Bevan D, Machin S, Scully MA. Thrombotic thrombocytopenic purpura precipitated by acute pancreatitis: a report of seven cases from a regional UK TTP registry. Br J Haematol. 2009;144:430-3.

32. Muñiz AE, Barbee RW. Thrombotic thrombocytopenic purpura (TTP) presenting as pancreatitis. J Emerg Med. 2003;24:407-11.

33. Qahtani SA. Acute renal failure and severe rhabdomyolysis in a patient with resistant thrombotic thrombocytopenic purpura. Int J Gen Med. 2011;4:687-9.

34. Ikhlaque N, Chang JC. Thrombotic Microangiopathy presenting as fulminating rhabdomyolysis with multiorgan dysfunction. Hospital Physician. 2003;39(6):51-6.

35. Burrus TM, Mandrekar J, Wijdicks EF, Rabinstein AA. Renal failure and posterior reversible encephalopathy syndrome in patients with thrombotic thrombocytopenic purpura. Arch Neurol. 2010;67:831-4.

36. Bakshi R, Shaikh ZA, Bates VE, Kinkel PR. Thrombotic thrombocytopenic purpura: brain CT and MRl findings in 12 patients. Neurology. 1999;52:1285-8.

37. Vaziri S, Navabi J, Afsharian M, et al. Crimean congo hemorrhagic fever infection simulating thrombotic thrombocytopenic purpura. Indian J Hematol Blood Transfus. 2008;24:35-8. 
38. Deepanjali S, Naik RR, Mailankody S, Kalaimani S, Kadhiravan T. Dengue Virus Infection Triggering Thrombotic Thrombocytopenic Purpura in Pregnancy. Am J Trop Med Hyg. 2015;93:1028-30.

39. Ardalan MR, Tubbs RS, Chinikar S, Shoja MM. Crimean-Congo haemorrhagic fever presenting as thrombotic microangiopathy and acute renal failure. Nephrol Dial Transplant. 2006;21:2304-7.

40. Lopes da Silva R. Viral-associated thrombotic microangiopathies. Hematol Oncol Stem Cell Ther. 2011;4(2):51-9.

41. Booth KK, Terrell DR, Vesely SK, George JN. Systemic infections mimicking thrombotic thrombocytopenic purpura. Am J Hematol. 2011;86:743-51.

42. Chang JC, Shipstone A, Llenado-Lee MA. Postoperative thrombotic thrombocytopenic purpura following cardiovascular surgeries. Am J Hematol. 1996:53:11-7.

43. Naqvi TA, Baumann MA, Chang JC. Post-operative thrombotic thrombocytopenic purpura: a review. Int J Clin Pract. 2004;58:169-72.

44. Venkata C, Kashyap R, Farmer JC, Afessa B. Thrombocytopenia in adult patients with sepsis: incidence, risk factors, and its association with clinical outcome. J Intensive Care. 2013;1:9.

45. Tsirigotis P, Chondropoulos S, Frantzeskaki F, et al. Thrombocytopenia in critically ill patients with severe sepsis/septic shock: Prognostic value and association with a distinct serum cytokine profile. J Crit Care. 2016;32:9-15

46. Kutcher ME, Redick BJ, McCreery RC, et al. Characterization of platelet dysfunction after trauma. J Trauma Acute Care Surg. 2012;73:13-9.

47. Shamseddine A, Chehal A, Usta I, Salem Z, El-Saghir N, Taher A. Thrombotic thrombocytopenic purpura and pregnancy: report of four cases and literature review. J Clin Apher. 2004;19:5-10.

48. Nguyen TC, Carcillo JA. Bench-to-bedside review: thrombocytopeniaassociated multiple organ failure-a newly appreciated syndrome in the critically ill. Crit Care. 2006;10:235.

49. Stravitz RT, Ellerbe C, Durkalski V, Reuben A, Lisman T, Lee WM. Acute liver failure study group. Thromobcytopenia is associated with multi-organ system failure in patients with acute liver failure. Clin Gastroenterol Hepatol. 2016:14:613-20

50. Nydam TL, Kashuk JL, Moore EE, et al. Refractory post-injury thrombocytopenia is associated with multiple organ failure and adverse outcomes. J Trauma 2011;70:401-406; discussion 406-7.

51. Lambris JD, Ricklin D, Geisbrecht BV. Complement evasion by human pathogens. Nat Rev Microbiol. 2008;6:132-42.

52. Markiewski MM, DeAngelis RA, Lambris JD. Complexity of complement activation in sepsis. J Cell Mol Med. 2008;12:2245-54.

53. Kerr H, Richards A. Complement-mediated injury and protection of endothelium: lessons from atypical haemolytic uraemic syndrome. Immunobiology. 2012;217:195-203.

54. Davies A, Lachmann PJ. Membrane defence against complement lysis: the structure and biological properties of CD59. Immunol Res. 1993;12:258-75.

55. Gene Cards. CD59 gene. http://www.genecards.org/cgi-bin/carddisp. pl?gene=CD59

56. Levi M, Löwenberg EC. Thrombocytopenia in critically ill patients. Semin Thromb Hemost. 2008;34:417-24

57. Mollnes TE, Fosse E. The complement system in trauma-related and ischemic tissue damage: a brief review. Shock. 1994;2:301-10.

58. Gilbert JS, Banek CT, Katz VL, Babcock SA, Regal JF. Complement activation in pregnancy: too much of a good thing? Hypertension. 2012;60:1114-6.

59. Bruins $P$, te Velthuis $H$, Yazdanbakhsh AP, et al. Activation of the complement system during and after cardiopulmonary bypass surgery: postsurgery activation involves C-reactive protein and is associated with postoperative arrhythmia. Circulation. 1997;96:3542-8.

60. Baldwin WM, Ota H, Rodriguez ER. Complement in transplant rejection: diagnostic and mechanistic considerations. Springer Semin Immunopathol. 2003;25:181-97.

61. Afshar-Kharghan V. The role of the complement system in cancer. J Clin Invest. 2017:127:780-9.

62. Ostrowski SR, Haase N, Müller RB, et al. Association between biomarkers of endothelial injury and hypocoagulability in patients with severe sepsis: a prospective study. Crit Care. 2015;19:191.

63. Zhang $C$. The role of inflammatory cytokines in endothelial dysfunction. Basic Res Cardiol. 2008;103:398-406.

64. van lerssel SH, Jorens PG, Van Craenenbroeck EM, Conraads VM. The endothelium, a protagonist in the pathophysiology of critical illness: focus on cellular markers. Biomed Res Int. 2014;2014:985813.
65. Aird WC. The role of the endothelium in severe sepsis and multiple organ dysfunction syndrome. Blood. 2003;101:3765-77.

66. Xing K, Murthy S, Liles WC, Singh JM. Clinical utility of biomarkers of endothelial activation in sepsis-a systematic review. Crit Care. 2012;16:R7.

67. van den Born BJ, Löwenberg EC, van der Hoeven NV, de Laat B, Meijers JC, Levi M, van Montfrans GA. Endothelial dysfunction, platelet activation, thrombogenesis and fibrinolysis in patients with hypertensive crisis. J Hypertens. 2011;29:922-7.

68. Bockmeyer CL, Claus RA, Budde U, et al. Inflammation-associated ADAMTS13 deficiency promotes formation of ultra-large von Willebrand factor. Haematologica. 2008;93:137-40.

69. Valentijn KM, van Driel LF, Mourik MJ, et al. Multigranular exocytosis of Weibel-Palade bodies in vascular endothelial cells. Blood. 2010;116:1807-16.

70. Bernardo A, Ball C, Nolasco L, Choi H, Moake JL, Dong JF. Platelets adhered to endothelial cell-bound ultra-large von Willebrand factor strings support leukocyte tethering and rolling under high shear stress. J Thromb Haemost. 2005;3:562-70.

71. Peyvandi F, Garagiola I, Baronciani L. Role of von Willebrand factor in the haemostasis. Blood Transfus. 2011;9(Suppl 2):s3-8.

72. Stockschlaeder M, Schneppenheim R, Budde U. Update on von Willebrand factor multimers: focus on high-molecular-weight multimers and their role in hemostasis. Blood Coagul Fibrinolysis. 2014;25:206-16.

73. Dhanesha N, Prakash P, Doddapattar P, et al. Endothelial Cell-Derived von Willebrand Factor Is the Major Determinant That Mediates von Willebrand Factor-Dependent Acute Ischemic Stroke by Promoting Postischemic Thrombo-Inflammation. Arterioscler Thromb Vasc Biol 2016. 36:1829-37.

74. Verhenne S, Denorme F, Libbrecht S, et al. Platelet-derived WWF is not essential for normal thrombosis and hemostasis but fosters ischemic stroke injury in mice. Blood. 2015:126:1715-22.

75. Crawley JT, Scully MA. Thrombotic thrombocytopenic purpura: basic pathophysiology and therapeutic strategies. Hematology Am Soc Hematol Educ Program. 2013;2013:292-9.

76. Nguyen TC, Liu A, Liu L, et al. Acquired ADAMTS-13 deficiency in pediatric patients with severe sepsis. Haematologica. 2007;92:121-4.

77. Feng S, Eyler SJ, Zhang Y, et al. Partial ADAMTS13 deficiency in atypical hemolytic uremic syndrome. Blood. 2013;122:1487-93.

78. Pourrat $\mathrm{O}$, Coudroy $\mathrm{R}$, Pierre F. ADAMTS13 deficiency in severe postpartum HELLP syndrome. Br J Haematol. 2013;163:409-10.

79. Gandhi C, Motto DG, Jensen M, Lentz SR, Chauhan AK. ADAMTS13 deficiency exacerbates WWF-dependent acute myocardial ischemia/ reperfusion injury in mice. Blood. 2012;120:5224-30.

80. Fujioka M, Hayakawa K, Mishima K, et al. ADAMTS13 gene deletion aggravates ischemic brain damage: a possible neuroprotective role of ADAMTS13 by ameliorating postischemic hypoperfusion. Blood. 2010;115:1650-3.

81. Yu WL, Leung T, Soo Y, Lee J, Wong KS. Thrombotic thrombocytopenic purpura with concomitant small- and large-vessel thrombosis, atypical posterior reversible encephalopathy syndrome and cerebral microbleeds. Oxf Med Case Reports. 2015;2015:179-82.

82. Ibernon M, Moreso F, Carreras L, et al. Thrombotic thrombocytopenic purpura with severe large artery branch involvement. Nephrol Dial Transplant. 2005:20:467-8.

83. Obrig TG, Louise CB, Lingwood CA, Boyd B, Barley-Maloney L, Daniel TO. Endothelial heterogeneity in Shiga toxin receptors and responses. J Biol Chem. 1993;268:15484-8.

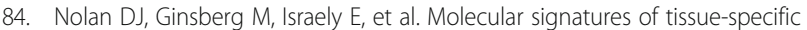
microvascular endothelial cell heterogeneity in organ maintenance and regeneration. Dev Cell. 2013;26:204-19.

85. Aird WC. Endothelial Cell Heterogeneity. Cold Spring Harb Perspect Med. 2012;2:a006429.

86. Proulx F, Seidman EG, Karpman D. Pathogenesis of Shiga toxin-associated hemolytic uremic syndrome. Pediatr Res. 2001;50:163-71.

87. Cooperberg AA. Acute promyelocytic leukemia. Can Med Assoc J. 1967:97: 57-63.

88. Dunoyer-Geindre S, Rivier-Cordey AS, Tsopra O, Lecompte T, Kruithof EKO. Effect of ATRA and ATO on the expression of tissue factor in NB4 acute promyelocytic leukemia cells and regulatory function of the inflammatory cytokines TNF and IL-1 $\beta$. Ann Hematol. 2017;96:905-17.

89. Levi $M$, van der Poll T. A short contemporary history of disseminated intravascular coagulation. Semin Thromb Hemost. 2014;40:874-80. 
90. McKay DG. Progress in disseminated intravascular coagulation. Calif Med 1969;111:186-198 contd.

91. McKay DG. Progress in disseminated intravascular coagulation part II. Calif Med. 1969;111:279-90

92. Sueishi K, Takeuchi M. Pathology of disseminated intravascular coagulation. Nihon Rinsho. 1993:51:30-6.

93. Gando S, Levi M, Toh CH. Disseminated intravascular coagulation. Nat Rev Dis Primers. 2016;2:16037.

94. Boral BM, Williams DJ, Boral LI. Disseminated Intravascular Coagulation. Am J Clin Pathol. 2016;146:670-80.

95. Wu Y, Luo L, Niu T, et al. Evaluation of the new Chinese Disseminated Intravascular Coagulation Scoring System in critically ill patients: A multicenter prospective study. Sci Rep. 2017;7:9057.

96. Toh CH, Alhamdi Y, Abrams ST. Current Pathological and Laboratory Considerations in the Diagnosis of Disseminated Intravascular Coagulation. Ann Lab Med. 2016;36:505-12.

97. Levi M, Scully M. How I treat disseminated intravascular coagulation. Blood. 2018;131:845-54

98. Kotiah SD. Besa EC. Acute promyelocytic leukemia clinical presentation. http://emedicine.medscape.com/article/1495306-clinical

99. Chang JC, Gross HM, Jang NS. Disseminated intravascular coagulation due to intravenous administration of hetastarch. Am J Med Sci. 1990;300:301-3.

100. He B, Hu S, Qiu G, Gu W. Clinical characteristics of acute promyelocytic leukemia manifesting as early death. Mol Clin Oncol. 2013;1:908-10.

101. Daver N, Kantarjian H, Marcucci G, et al. Clinical characteristics and outcomes in patients with acute promyelocytic leukaemia and hyperleucocytosis. Br J Haematol. 2015;168:646-53.

102. Kaneko T, Wada H. Diagnostic criteria and laboratory tests for disseminated intravascular coagulation. J Clin Exp Hematop. 2011;5:67-76.

103. Slofstra SH, Spek CA, ten Cate H. Disseminated intravascular coagulation. Hematol J. 2003:4:295-302.

104. Franchini M, Lippi G, Manzato F. Recent acquisitions in the pathophysiology, diagnosis and treatment of disseminated intravascular coagulation. Thromb J. 2006:4:4.

105. Chen VM, Hogg PJ. Encryption and decryption of tissue factor. J Thromb Haemost. 2013:11(Suppl 1):277-84.

106. Versteeg HH, Ruf W. Thiol pathways in the regulation of tissue factor prothrombotic activity. Curr Opin Hematol. 2011;18:343-8.

107. Rauch U, Bonderman D, Bohrmann B, et al. Transfer of tissue factor from leukocytes to platelets is mediated by CD15 and tissue factor. Blood. 2000;96:170-5.

108. Esmon $C T$. The interactions between inflammation and coagulation. Br J Haematol. 2005;131:417-30.

109. Petäjä J. Inflammation and coagulation. An overview. Thromb Res. 2011; 127(Suppl 2):S34-7.

110. Demetz G, Ott I. The Interface between Inflammation and Coagulation in Cardiovascular Disease. Int J Inflam. 2012;2012:860301.

111. Levi M, van der Poll T. Inflammation and coagulation. Crit Care Med. 2010;38(2 Suppl):S26-34.

112. Taylor FB Jr, Wada H, Kinasewitz G. Description of compensated and uncompensated disseminated intravascular coagulation (DIC) responses (non-overt and overt DIC) in baboon models of intravenous and intraperitoneal Escherichia coli sepsis and in the human model of endotoxemia: toward a better definition of DIC. Crit Care Med. 2000;28(9 Suppl):S12-9.

113. Taylor FB Jr, Kinasewitz GT. The diagnosis and management of disseminated intravascular coagulation. Curr Hematol Rep. 2002;1:34-40.

114. Fourrier F. Severe sepsis, coagulation, and fibrinolysis: dead end or one way? Crit Care Med. 2012;40:2704-8.

115. Marshall JC. Why have clinical trials in sepsis failed? Trends Mol Med. 2014; 20:195-203.

116. Kularatne SA, Imbulpitiya IV, Abeysekera RA, Waduge RN, Rajapakse RP, Weerakoon KG. Extensive haemorrhagic necrosis of liver is an unpredictable fatal complication in dengue infection: a postmortem study. BMC Infect Dis. 2014;14:141

117. Talwani R, Gilliam BL, Howell C. Infectious diseases and the liver. Clin Liver Dis. 2011;15:111-30.

118. Samanta J, Sharma V. Dengue and its effects on liver. World J Clin Cases. 2015;3:125-31.

119. El Sayed SM, Abdelrahman AA, Ozbak HA, et al. Updates in diagnosis and management of Ebola hemorrhagic fever. J Res Med Sci. 2016;21:84.
120. Mammen EF. Coagulation abnormalities in liver disease. Hematol Oncol Clin North Am. 1992;6:1247-57.

121. Uemura M, Fujimura $Y$, Ko S, Matsumoto M, Nakajima Y, Fukui $H$. Determination of ADAMTS13 and Its Clinical Significance for ADAMTS13 Supplementation Therapy to Improve the Survival of Patients with Decompensated Liver Cirrhosis. Int J Hepatol. 2011;2011:759047.

122. van Dongen PW, Eskes TK, Gimbrère JS, Snel P. Maternal mortality due to the hepatorenal syndrome of pre-eclampsia. A case report. Eur J Obstet Gynecol Reprod Biol. 1979;9:299-306.

123. Isler CM, Rinehart BK, Terrone DA, May WL, Magann EF, Martin JN Jr. The importance of parity to major maternal morbidity in the eclamptic mother with HELLP syndrome. Hypertens Pregnancy. 2003;22:287-94.

124. Agarwal B, Wright G, Gatt A, Riddell A, Vemala V, Mallett S, Chowdary P, Davenport A, Jalan R, Burroughs A. Evaluation of coagulation abnormalities in acute liver failure. J Hepatol. 2012;57:780-6.

125. Senzolo M, Burra P, Cholongitas E, Burroughs AK. New insights into the coagulopathy of liver disease and liver transplantation. World J Gastroenterol. 2006;12:7725-36.

126. Malla K, Malla T, Hanif M. Prognostic indicators in haemolytic uraemic syndrome. Kathmandu Univ Med J (KUMJ). 2004;2:291-6.

127. Tsai MH, Peng YS, Chen YC, et al. Adrenal insufficiency in patients with cirrhosis, severe sepsis and septic shock. Hepatology. 2006:43:673-81128.

128. Franchini M, Manzato F, Salvagno GL, Lippi G. Potential role of recombinant activated factor $\mathrm{VII}$ for the treatment of severe bleeding associated with disseminated intravascular coagulation: a systematic review. Blood Coagul Fibrinolysis. 2007;18:589-93.

129. Román E, Mendizábal S, Jarque I, et al. Secondary thrombotic microangiopathy and eculizumab: A reasonable therapeutic option. Nefrologia. 2017;37:478-91.

130. Brocklebank V, Kavanagh D. Complement C5-inhibiting therapy for the thrombotic microangiopathies: accumulating evidence, but not a panacea. Clin Kidney J. 2017;10:600-24.

131. Nangaku M, Alpers CE, Pippin J. CD59 protects glomerular endothelial cells from immune-mediated thrombotic microangiopathy in rats. J Am Soc Nephrol. 1998:9:590-7.

\section{Ready to submit your research? Choose BMC and benefit from:}

- fast, convenient online submission

- thorough peer review by experienced researchers in your field

- rapid publication on acceptance

- support for research data, including large and complex data types

- gold Open Access which fosters wider collaboration and increased citations

- maximum visibility for your research: over $100 \mathrm{M}$ website views per year

At BMC, research is always in progress.

Learn more biomedcentral.com/submissions 